\title{
The System of Protected Areas in Bulgaria in Terms of the Implementation of the Concepts of Sustainable and Alternative Tourism
}

\author{
Georgiev Leonidov Georgi ${ }^{A}$ \\ Received: April 2010 | Revised: May 2010 | Accepted: May 2010
}

\begin{abstract}
Protected areas hold a special position in terms of the sustainable socio-economic and tourism development of the planet. The International Union for Conservation of Nature has created a specific classifying system for categorization of such areas depending on their nature-scientific and conservation value and significance. Except for preserving valuable biological species and their natural habitats, these areas could fulfill one more function. They can be integrated and contribute to the sustainable development of all spheres of socio-economic life of the community.

This paper sets the aim to determine to what extent and what categories of protected areas in Bulgaria could be integrated into the tourism sector of the country and to contribute that way to its sustainable development. Ecotourism is considered as main tool to achieve this goal. Two concepts are laid upon its successful implementation. These are the concept for sustainable development and the one for development of alternative forms of tourism. The thesis that the concept for development of alternative forms of tourism is thought to compliment the one for development of sustainable tourism.
\end{abstract}

Key words: biodiversity, protected areas, ecotourism, alternative tourism.

\section{Introduction}

The rapid industrial development undergoing for the last decades of the XX century has lead to a series of socio-economic transformations causing serious negative impact on the natural resources of the planet. The idea for sustainable development has emerged as an answer resulting from the deep impact of the negative trends.

Protected areas are of special importance for the long-term sustainability of nature for their diversity of plant and animal species and valuable genetic fund. Furthermore their significance in the scope of nature conservation predetermines their overall role for the sustainable development of the socio-economic living of people on the Earth. Due to the fact that they have specific nature and characteristics the International Union for Conservation of Nature has adopted a special system for categorization of different types of protected are- as. The main criteria for their classification represent their nature-scientific and conservation values. One of the newly adopted functions of these areas is their application in tourism concerning their eco-friendly exploitation for the purposes of sustainable tourism.

This paper aims to reveal to what categories of Bulgarian protected areas could be used for the purposes of sustainable tourism practices. Subject of analysis are the concept for sustainable tourism development as well as the concept for development of alternative forms of tourism. Under observation are various types of protected areas in the country as well as special protection areas under NATURA 2000. On the basis of the assessment for their prospective integration within the scope of tourist products some conclusions and recommendations are made.

\footnotetext{
A South West University Neofit Rilski; Tourism Department at the Faculty of Economics; 66 Ivan Mihaylov str., 2700 Blagoevgrad, Bulgaria; e-mail: glgeorgiev@abv.bg
} 


\section{Materials and methods}

For the purposes of this research there have been used recognizable methods and approaches for collection of data. Some sources have been used, provided by the Ministry of Environment and Water, the Directories of Bulgarian National and $\mathrm{Na}-$ ture parks, and all I5 Regional Inspections on Protection of Environment and Water, the Ministry of Economy, Energy and Tourism, the Ministry of Regional Development and Public Works, the Ministry of Agriculture and Food, the Executive Forest Agency, research publications from international scientific forums, dedicated to biodiversity and protected areas, as well as a series of publications of Bulgarian and foreign authors. The analysis is conducted and the results have been established by the means of comparative and analytical approaches. Last, but not least personal observations in some of the protected areas have been conducted. The working methods that have been used for the purposes of this research include description, diagnosis, analysis and synthesis, comparison, statistical and expert methods.

\section{Discussion and analysis}

\section{Conceptual background}

The concept for sustainable development was created in the 70-ies of the XX century, laying an emphasis upon the relationship between environment and economics. The decision for the foundation of the UN Programme on environment was taken at the World conference on human development (Stockholm, I972). It got further popularization thanks to the paper of the World Commission on Environment and Development (I987), which added a human implication of idea for sustainable development. This document facilitated the temp of development of the idea for sustainability and lead to a series of debates related to its content. The International Union for Conservation of Nature (IUCN), the UN Programme on Environment (UNEP) and the World Wildlife Fund (WWF) launched a joint publication called Strategy for sustainable life on the Earth, where they further developed the definition of this term, considering it as "an improvement of living standards and quality of life with a view to the possible capacity of the sustaining ecosystems".

A new stimulus was given at the Conference on Environment and Development (Rio, I992). The conference resulted in the adoption of a special plan, titled Agenda 2I, has turned into a basis for lots of international, national and local initiatives aimed at sustainable development. The first of them is: "The man is a central unit in terms of all matters related to sustainable development, aiming at preservation of human health and ensuring improved living standards in harmony with environment." This is considered as a completely new development philosophy, based on the integration of the social, ecological and economic aspects of community life, intended to ensure the standard of living and labour of the future generations. Since the beginning of the new millennium the concept for sustainable development has been considered by an increasing number of organizations as the only possible balance between business interests, the community and what is more important by the future generations. The forum in Johannesburg in 2002 was dedicated to the further development and applying the Rio decisions to practice.

The definition "sustainable tourism" is a new one, considered as a further development of the idea for sustainable tourism, launched during the Rio Conference (1992). The aim of this tourism form is not only to minimize the impact over the biological environment, but also to create conceptions for the periods before, during and after tourist trips, as well as to evoke nature-friendly tourism practices at the stage of development of emitive markets. This is a form of tourism evolution developed with a view to the interests of the hosting community on the one hand and with visitors in mind, on the other hand. All activities on site should consider the permitted capacity of the natural resources, or in other words to keep the principles of cost-effective use of the resources.

Despite the fact, that the above mentioned two concepts are subject to debate, at theoretical, operational and practical level for the purposes of this paper we have considered the definition, given by the EUROPARC Federation of the European National and Natural parks ${ }^{\mathrm{I}}$. According to this definition "sustainable tourism encompasses all forms of tourism development, management and activities, that preserve nature, contribute to the social and economic integration and to the wellbeing of the natural, anthropogenic and cultural resources over time". From this point of view the following prerequisites should be fulfilled in order to ensure tourism development:

\footnotetext{
1 The Federation of the European Natural and National Parks (EUROPARC) is established in I973. It unites the national, regional natural parks and biosphere reserves in 39 countries within the Old continent. Their common purpose is to preserve and protect the European wildlife, habitats and landscapes. Since then it is affirmed as an independent, non-government organization. Its membership means mutual responsibility for approximately 400 protected areas. The EUROPARC activities are coordinated by an international team of professionals based in the headquarter of the organization inGrafenau, National Parc "Bavarian Forest"- Germany.
} 
- to create economic benefits for both tourists and the local community as part of a balanced economy;

- to reflect the needs of the local community the latter to be an active participant in decision-making processes; to ensure employment of the local labour force at all levels of tourism activities as well as to place an emphasis upon tourism development and profitable and attractive jobs;

- not to be elite-oriented and to contribute to a balanced development of international and domestic tourism;

- the scope of development to be made with a view to the opportunities of the hosting territory and its specific resources -environment, history and culture;

- to take into consideration the fact that the physical and cultural environment are of eternal value, which does not exceed their value as tourist resources. For that reason they should not have only short-term impact, but also to serve the future generations (Rakadziyska, 2007).

The concept for development of alternative forms of tourism compliments further the concept for sustainable tourism. Furthermore, it reveals some approaches leading to the desired final results (Rakadziyska, 2007).

Alternative tourism is considered as "transformation of the three dominant models of tourism development in three aspects - socio-cultural and tourism ethics, economic realism and environmental protection (Wackermann, I988).

The author thinks that alternative tourism could not exist without alternative forms of hospitality, services and appropriate staff qualifications. That way alternative form of tourism is considered as a dynamic system, determined not only for its structural elements, but for its stable, mandatory and simultaneously existing "living" relations among these elements, which contribute to the demolishment of the disadvantages of contemporary tourism. Furthermore they lead to concentration on tourist flows, improvisation of tourism processes, mass "take-over" of great areas, dissemination of advertisement and product cliché (Wackermann, 1988; Rakadziyska, 2007).

The existing similar forms of tourist products as well as the arising "gigantism" could not meet the requirements of tourists, whose travel choice is based on specific motivation. Alternative tourist products are expected to offer original combinations of the elements of the nature and the anthropogenic environment, which in turn ensure safety, tranquility and comfort together with specific effects such as regulation of the tourist visit on spe- cific sites. That way alternative forms of tourism appear to be opposite to the massive tourism.

Very often in literature alternative form of tourism is determined as "soft", "mild", "local" differing from the definition "tough" which is used to describe mass tourism (Rakadziyska, 2007).

According to the Bulgarian Association for Alternative Tourism (BAAT) alternative forms of tourism unite tourist packages or individual tourist services, defined as alternative to the mass tourist products for their methods of supply, implementation and human resource engagement.

The complex set of motives of tourists, undertaking travel has served as a prerequisite for development of specific types of tourism services and products, which on the other hand have lead to a disability to establish a common term, describing this form of tourism in lots of countries. Some of the most wide spread terms in Bulgaria include specific tourism, alternative tourism and etc. English literature, on the other hand abounds in terms such as "special interest travel", "alternative tourism", "responsible tourism", "soft tourism" and etc. Medlik (1996) thinks that the majority of these terms are synonymous and they have similar meaning and scope of content. They are similar as they all describe tourism forms, which do not have a destructive influence. On the contrary, they generate positive social, cultural and ecological impact over tourist sites and for that reason they are considered as alternative to the mass tourism (Mileva, 2004).

The author points out that alternative tourism has the following characteristics - limited scope of extent, travel customization and independence, small number of tourist groups, tolerant attitude toward the hosting community and preservation of their customs, traditions and values. Another essential feature of alternative tourism is the fact that it could not be referred and considered as a mass form of tourism. For that reason very often other tourism types which differ from mass tourism are defined as "alternative tourism".

The World Tourism Organization recommends keeping to the following set of principles contributing to efficient implementation of the concepts for sustainable and alternative tourism development in the market economy (Rakadziyska et al, 2007):

- involvement of all social groups of the local community in the process of tourism development within the hosting territory, as well as ensuring transparent information about the processes on the overall market;

- establishment of a collective responsibility in the processes of planning, decision-making, problem solving, project implementation and assessment; 
- execution a system approach aimed at integrative problem solving in the social and economic spheres instead of finding solutions only for its individual elements;

- use of ecological limitations, allowing tourism development in predefined values;

- equality in the eye of the law, keeping to human rights, relations and collaboration development on a global scale;

- implementation of a long-term strategic planning with a view to the future.

Taking into consideration the fact that there is not a "zero" impact over the tourism development, the balance of economic purposes with social ambience and environment could ensure minimization of all negative effects. The most popular forms of alternative tourism represent ecotourism, rural tourism, yachting and hobby tourism, "language vacations" and etc

The increasing level of community awareness concerning environment, together with the progress in communication services made ecotourism one of the most fast-developing sectors within the travel industry. Despite the fact that the market share of ecotourism is relatively small compared to the one of conventional tourism, its annul revenues come to approximately 20 billion dollars. Together with that expenditures for the same tourism type increase by $20 \%$, which is five times more than the average increase of the overall tourism industry.

\section{Development of alternative tourism in Bulgaria}

A solid basis for development of this tourism form in Bulgaria represents the existing system of protected areas, proclaimed by the Law on protected areas (I998) and protected sites under NATURA 2000.

Despite the existing negative effects, resulting from the overbuilding processes, implemented into the majority of the Bulgarian sea and mountain resorts, there is a trend toward an increase in the prospective market of tourist products within the scope of sustainable tourism, including ecotourism. A survey, conducted by the State Agency for Tourism in the summer of 2008 , revealed that $\mathrm{I} 8,3 \%$ of the surveyed individual tourists, have arrived in the country for ecotourism purposes. The latter is also pointed as one of the three most popular accompanying activities, supplementing the main purpose of visit (the sea tourism) together with SPA $(25, \mathrm{I} \%)$ and ethnographic tourism (I9,I). The collected data shows an increasing interest toward tourism among nature and diversification of tourist stay through practice of specialized tourism forms. Despite that at the current stage the main characteristic of Bulgarian tourism represents its distinctive monostructure and territorial concentration. On the global international market our country is recognized mainly as destination for summer and winter tourism. (offering sea and ski tourist products). Moreover, taking into consideration the fact that the number of accommodation establishments within the internal country increases, the majority of them are located along the Black Sea coast, mountain resorts, the cities of Sofia and Plovdiv. The majority number of tourists visit the country in the summer months with the aim to have sea holidays. Similar trend is registered with a view to the currency incomes as one third of the annual incomes is generated in the summer months July and August. It is obvious that Bulgarian tourist products have to be diversified with new tourism forms. The latter could contribute to minimize the seasonality and the territorial disproportions, creating new opportunities for sustainable use of the existing resources as well as to facilitate the regional and local development. The natural and cultural resources needed for ecotourism development draw attention among Bulgarian and international tourists. For that reason a lot of agencies, family hotels, guest houses and sport clubs have been established with the aim to supply services in this field, which in turn has a positive impact on the development of specialized tourism forms. Despite that the successful development of ecotourism is seriously threatened by the lack of funds and stimulus, building processes within the boundaries of the protected areas and protection areas under the Bird and Habitat directives or unreliable management.

The sustainable development of this tourism form creates an opportunity for economic revival of the most low-developed regions in the country. However, there are a lot of factors such as the expected decrease in tourism demand and the climate changes which modify the images and designation of tourist destinations. These factors together with the severe market competition reveal that development of sustainable forms of tourism would be one of the most beneficial forms of tourism with a view to the long-term tourism development in the country. On the other hand this could contribute to minimize the negative effects on the global market. (National programme and action plan for ecotourism development in Bulgaria 2009 - 2013).

Ecotourism is defined as a nature-based tourism. For the last several years the professionals working in this filed consider it as an instrument, contributing to sustainable development. The latter could be used as a tool leading to transition in the public and economic life which in turn could 
achieve a balance among natural and cultural resources, the implemented economic results, standards and quality of life and etc. As a result the term ecotourism is used as a definition concerning the principles of sustainable development, while on the other hand it describes a tourism market segment.

Ecotourism is also an opportunity for development of all aspects of business services related to this tourism form, placing a priority on small local entrepreneurship initiatives, ensuring social and economic activity of the local community as well as equitable distribution of benefits and responsibilities. On the other hand ecotourism includes also important elements of natural scientific education, interpretation of the natural and cultural heritage and what is more, it complies with all forms of sustainable tourism. The clear and accurate interpretation of ecotourism toward the principles, managing directions, certification of its sustainability hold a special place for it in the scope of tourism sector. It also constitutes an integral part of an enlarging market niche of the tourism industry. This means that there is a trend toward a dynamic growth of the country in terms of the prospective market of ecotourism products. There are opportunities for the country to become a regional and European leader in this developing market (National strategy for ecotourism, 2004). The established form of environment protection represents the system of National parks and other areas of similar designation. The foundation of the Yellowstone National Park (USA,I872) marked the initial stage of creation and adoption of the concept for managed areas of this kind. The idea for establishment of national parks and other protected areas spread over various countries over time. Serious attempts toward establishment of international collaboration in this field as well as in defining the term National Park are made over time (London, I933, Washington, I940; Delhi,I969; Part,Avstralia,I990 and etc) until I994 when the International Union for Conservation of Nature, after more than twenty years of work, managed to create and offer a common classification of the protected areas, applicable to various countries. The opportunity to apply certain type of protected areas to any of the categories allowed those, who manage them to share the experience of their fellow-mates around the world working in partnerships with them. The main criterion for classifying protected areas into categories is the purpose of their governance The system of protected areas of IUCN supports the national legislation bodies in the countries to develop their own systems of protected areas, as well as to set the main indicators of their management. (The green gold of Bulgaria, 2000).
According to IUCN the starting point in determining the category of protected areas should be their definition. The latter was adopted during the Fourth World Congress of the National and Nature Parks and protected areas. In terms of that they represent a land territory or aquatory, designated for biodiversity protection and conservation as well as for their natural and cultural values, which are maintained through legislative or other efficient means.

This definition encompasses the combination of protected areas and all categories should comply with it. It is necessary to mention that despite the fact that all types of protected areas meet the requirements of this term, the specific purposes and tasks for which they are proclaimed as protected areas are of different character.

The main purposes of governance include:

- nature-scientific activities;

- protection of the original status of nature;

- conservation of species and genetic fund;

- preservation of the environmental functions;

- protection of natural and cultural sites and landmarks;

- recreation and tourism;

- education

- long-term use of the natural ecosystems;

- maintenance of cultural and traditional characteristics.

In accordance with IUCN (1994) it is considered that of greatest importance for the biodiversity protection are the Strict Reserves, the National and Nature (regional) Parks and etc. Managed reserves.

Furthermore, for the last 30 - 40 years serious measures were undertaken with the aim to establish international collaboration for the protection of biodiversity and protected areas on regional and global scale.

Other international documents and initiatives of importance include the Convention on the biodiversity, the Convention on the conservation of the European wildlife and Natural habitats (Bern convention), Convention on the international trade in endangered species of wild flora and fauna (Washington, CITES), Convention on the protection of migratory species of wild animals (Bonn convention), Convention on Wetlands of International importance especially as waterfowl habitat (Wetland convention, Ramsar convention), Convention on the protection of the Black sea against pollution (The Black sea biodiversity and landscape conservation protocol), Convention concerning the protection of the world natural and cultural heritage, European landscape convention, Council Directive 79/409 EEC on the conservation of wild birds, the European Direc- 
tive $92 / 43$ on the conservation of natural habitat and of wild flora and fauna, UNESCO MAB Programme "Man and Biodiversity" concerning the establishment of a world network of biosphere reserves; Birdlife International Programme concerning the wetlands of international importance, CORINE Programme; Plantlife International Programme concerning the floristic sites of importance, Agreement on the conservation of populations of whale-like mammals in the Black sea, the Agreement on the conservation of populations of European bats, Agreement on the conservation of populations of whale-like mammals in the Black sea, Mediterranean Sea and the neighbouring aquatories of the Atlantic ocean, the European network of protected areas "PAN PARKS" and etc.

Bulgaria started its reservation activity more than seventy-five years ago. The governance and management of the protected areas is done on the basis of the Law on the protected areas (I998). The categories of Bulgarian protected areas comply with the IUCN classification (I994). In Bulgaria are proclaimed 3 National Parks with total area of I93 047,9 ha (Table I), II Nature Parks encompassing 275 447,8 ha (Table 2), 35 Managed reserves with area of 4 57I, 9 ha; 55 Reserves comprising of 77 I24,05 ha; 449 Protected localities comprising of 72884,05 ha and 349 Natural landmarks which area is I8 I75,4I ha. In total the protected areas in Bulgaria encompass 64I 25I ha, accounting for $0,57 \%$ of the territory of the country (Figure I).

The ecological network of protection areas NATURA 2000 is also relevant to some extent with the conservation of the biodiversity as it encompasses protected areas. It represents an in- strument of the European Community aimed at conservation of the habitats and animal species of importance for the Community. The establishment of this ecological network is an obligation for each member-state of the European Union in accordance with the Bird Directive and Habitat Directive.

The contribution of NATURA 2000 for the overall process of biodiversity conservation represents the efforts of the latter to prevent the degradation, fragmentation and destruction of natural and semi-natural habitats, as well as habitats of rare and endangered animal species. The ecological network ensures a free geographical dissemination of species, genetic interchange and migration. Through NATURA 2000, the European Union participates in the establishment of EMERALD network, in conformity with the Bern convention, which encompasses the overall territory of Europe and some countries in Northern Africa.

The Bird directive was adopted on 02.04.I979 and came into force in I98I. It is intended to preserve the populations of the wild birds within the territory of the European Union together with the variety of habitats appropriate for conservation. For that reason special protected areas are established and the habitats within or outside their territories are managed, new biotopes are created and violated ones are revived. The rare, vulnerable and endangered species (the ones enlisted in Appendix I of this directive) and all regularly migratory birds are subject to special natural scientific activities in terms of their habitats. This in turn requires the establishment of Special Pro-

Table 1. National Parks in Bulgaria

\begin{tabular}{|c|c|c|c|c|}
\hline Name of the National Park & Area in ha & Region/ District & Name of the reserve & Reserve area in ha \\
\hline \multirow{4}{*}{ Rila National Park } & \multirow{4}{*}{$81,046.0$} & \multirow{4}{*}{$\begin{array}{l}\text { Pazardzik, Sofia, } \\
\text { Kyustendil, } \\
\text { Blagoevgrad }\end{array}$} & Parangalitza & 1509.0 \\
\hline & & & Ibar & 2248.6 \\
\hline & & & Central Rila reserve & 12393.7 \\
\hline & & & Skakavitza & 70.8 \\
\hline \multirow{2}{*}{ Pirin National Park } & \multirow{2}{*}{$40,332.4$} & \multirow{2}{*}{ Blagoevgrad } & Bayuvi dupki - Dzindzeritza & 2248.6 \\
\hline & & & Yulen & 3156.0 \\
\hline \multirow{8}{*}{$\begin{array}{l}\text { Central Balkan } \\
\text { National Park }\end{array}$} & \multirow{8}{*}{$71,669.5$} & \multirow{8}{*}{$\begin{array}{l}\text { Lovech, Gabrovo, Sofia, } \\
\text { Plovdiv, Stara Zagora }\end{array}$} & Boatin & 1597.2 \\
\hline & & & Tzarichina & 3418.7 \\
\hline & & & Kozyata stena & 904.3 \\
\hline & & & Steneto & 3578.8 \\
\hline & & & Peeshtite skali & 1465.7 \\
\hline & & & Severen Dzhndem & 1610.0 \\
\hline & & & Dzhendema & 4220.2 \\
\hline & & & Stara reka & 1974.7 \\
\hline
\end{tabular}


Table 2. Nature Parks in Bulgaria

\begin{tabular}{|c|c|c|c|c|c|}
\hline Name of the Nature Park & Area in ha & Reserve & Area in ha & $\begin{array}{l}\text { Managed } \\
\text { reserve }\end{array}$ & $\begin{array}{l}\text { Area of the Managed } \\
\text { reserve in ha }\end{array}$ \\
\hline \multirow{2}{*}{ Vitosha } & \multirow{2}{*}{$26,606.6$} & Bistrishko branishte & $1,060.6$ & \multirow{2}{*}{-} & \multirow{2}{*}{ - } \\
\hline & & Torfeno branishte & 785.3 & & \\
\hline Rusenski Lom & $3,408.0$ & - & - & - & - \\
\hline Sinite kamani & $11,380.8$ & Kutelka & 645.1 & - & - \\
\hline Shumensko Plato & $3,895.8$ & Bokaka & 62.6 & - & - \\
\hline Zlatni pyasatsi & $1,320.7$ & - & - & - & - \\
\hline Vrachanski Balkan & $30,129.9$ & Vrachanski Karst & $1,438.9$ & - & - \\
\hline \multirow{5}{*}{ Strandja } & \multirow{5}{*}{$116,068.5$} & Silkosia & 389.6 & & \\
\hline & & $\begin{array}{l}\text { Uzunbodzak - } \\
\text { Lopushna }\end{array}$ & 2,529.6 & & \\
\hline & & Vitanovo & $1,112.4$ & & \\
\hline & & Sredoka & 607.8 & & \\
\hline & & Tisovitsa & 749.3 & & \\
\hline Rila Monastery & $27,370.7$ & $\begin{array}{l}\text { Rila Monastery } \\
\text { Reserve }\end{array}$ & $3,676.5$ & & \\
\hline \multirow{2}{*}{ Persina } & \multirow{2}{*}{$21,762.2$} & Kitka & 25.4 & \multirow{2}{*}{ Persinski blata } & \multirow{2}{*}{385.2} \\
\hline & & Milka & 30.0 & & \\
\hline Bulgarka & $21,772.2$ & - & - & - & - \\
\hline Belasitsa & $11,732.4$ & Kongura & $1,320.0$ & - & - \\
\hline
\end{tabular}

tected Areas) and other actions, preventing pollution and deterioration of the habitats.

Specific measures aimed at preservation of the nesting bets, wintering sites and migratory routes are needed for the protection of the migratory birds. Special attention has to be paid at the wetlands of international importance (the Ramsar sites). Similar actions are intended also for the migratory birds, which are not enlisted in Appendix I. For their protection are established Special Protection Areas for the periods of nesting and migration along the migratory routes.

Directive 92/43 of the European Union for the Conservation of natural habitats and of wild flora and fauna was adopted on 25.05.1992. The member-states have the obligation to implement all necessary activities with the aim to transpose the directive requisites in their national legislations. The main purpose of this international initiative is to assist for the conservation of the biodiversity recognizing the local economic, cultural and regional characteristics. It is considered that this directive contributes to the implementation of the concept for sustainable development.

The essence of the directive represents its part, concerning conservation of natural habitats of species. There are six supplementary appendices to the directive.

Subject of protection in the scope of both directives are over I40 natural habitats and over 600

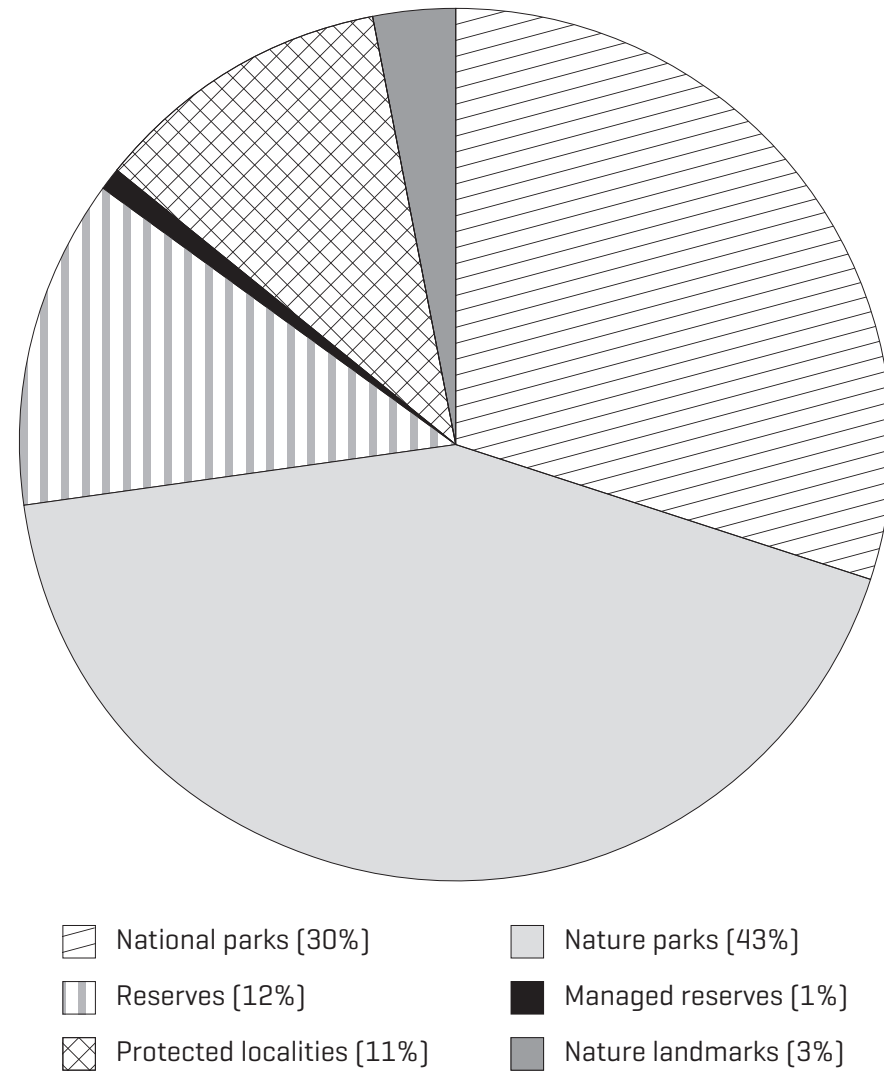

Figure 1 Distribution of the protected areas in Bulgaria in terms of their territory 
plant and animal species important for the Community. The member-states, as well as the acceding countries have the obligation to determine the locations of their natural habitats together with the species subject to protection.

In Bulgaria are adopted II4 zones for the protection of wild birds, covering $20.3 \%$ of the country as well as 228 zones for the protection of natural habitats, which account for $29.5 \%$ of the country. Their proclamation as protection zones is done with a decision of the Council of ministers. The total number of the protection zones under NATURA 2000 in the country up to date is 332 , which cover an area of $33.89 \%$ of its territory. Ten of all zones have common boundaries. .

It must be taken into consideration that there is a big discrepancy between the existing protected areas in the country (1998) and the protection zones, designated under the Law on the protection of biodiversity (2002).

Despite the directive regulation on the establishment of the European ecological network NATURA 2000, designation of such areas (protection zones according to the national legislation of Bulgaria) in member-states is to be done on the basis of relevant scientific data as well as the information, included in Appendix 3 of the directive. (article 7 of the Law on the protection of biodiversity). The purpose of the network NATURA 2000 is not to create strict natural reserves, where any forms of human activities are prohibited. The emphasis is placed on the ecological, economic and socially sustainable future management of these territories which complies with the conservation purposes of the protection zones. In lots of cases the existence or revival of traditional activities and ones, having positive influence is of essential importance for the preservation of the biodiversity, especially in agricultural regions and forestry enterprises.

It is important to emphasize that in the initial stage of selection of NATURA 2000 special protection areas within the territory of Bulgaria, very negative public reactions arised on behalf of economic organizations including tourism businesses. The reasons for the escalations resulted from the fact that in the scale of NATURA 2000 were included territories which are parts of Pirin National Park, Rila National Park, Central Balkan National Park, Pomirie lake, Ropotamo complex and many others areas, which are subject to investment interests. There is massive overbuilding in some of these territories where high-rated resort complexes are erected.

There are a lot of speculations in public that any kind of building and economic activities will be minimized. The fact that sustainability is one of the basic principles concerning the assimila- tion of NATURA 2000 protection zones, including all tourism activities, is totally neglected. This means that all planning activities, development of tourist infrastructure, its functionality and marketing have to be focused on ecological, social, cultural and economic criteria for sustainability.

In terms of the tourism sector the idea for sustainable ecological, economic and social development of the protection areas, included in NATURA 2000 could be achieved through a balanced management of different tourist activities, implemented within the boundaries of these zones. The latter implies strategic planning and management of such activities in the established eight tourism regions in Bulgaria.

In conformity with the plan for establishment of tourism regions within the country, the following eight tourism regions are to be created - Danube region, Region of Stara Planina, Sofia region, Region of Rila and Pirin, Rhodope region, Old Bulgarian capitals, Thrace region and Black Sea region. Within their territories are to be established subregions, microregions and tourism centres. The latter will represent the main structural units for tourism planning and management of the regions.

\section{Conclusions}

Despite their tourism product profile each region and special protection areas on their territory as well as all activities aimed at natural habitats and /or animal species conservation also require measuring and evaluation of the level of tourism activity with a view to the ecological standards and their long-term sustainability. In a narrow sense this means that the establishment of tourist centers of the regions together with the key tourism destinations within their boundaries and places of visitation have to be located outside the territory of the special protection areas. The latter is of key importance with a view to the fact that tourism centres and destinations are subject to massive building activities of tourism complexes and specialized super - and infrastructure. Furthermore they are usually points of highest concentration of tourist flows and feature intensified level of tourism activity. The intensity of recreational and tourism exploitation have to be in designated limits for the scope of the special protection areas. With a view to this fact, it is strongly recommended to take into consideration figure 4 in the process of Management plan preparation. The map includes all special protection areas, located within the boundaries of the eight tourist regions.

On the basis of the above analysis, the following conclusions can be made: 
I. Development of alternative forms of tourism is one of the most effective ways for assimilation of the most significant in natural scientific value natural tourism resources. Very suitable for this purpose are the special protection areas, combining the opportunities for economic and conservation activities;

2. Alternative tourism forms contribute to minimize the negative anthropogenic impact, caused by mass tourism. That way they facilitate sustainable tourism and socio-economic development of tourist regions;

3. Tourism centers and main destinations of the tourist regions in Bulgaria could be locations, within the boundaries of the special protection areas under NATURA 2000 as well as in some categories of protected areas (except for the reserves and managed reserves under category la and IV of IUCN);

4. Special protection and protected areas (except for the areas under categories la and IV) allow different tourism activities to be implemented, but their scale and level of extent have to comply with the requirements of sustainability standards;

5. Involvement of universities and scientific institutes in NATURA 2000 activities through development of specially designed programs for exchange of academic lectures, participations in joint projects and partnership with the con- trolling bodies under this international initiative.

\section{References}

Baker, S. 2006. The concept of sustainable development. In Sustainable Development London, Routledge, I7-48 pp.

Georgiev, G. 2009. Nature under protection. National and nature parks and reserves in Bulgaria. Publishing House Geya Libris, Sofia, 287 pp. (in Bulgarian)

The green gold of Bulgaria, 2000. Ministry of Environment and Waters, Sofia, II4 pp.

National strategy and action plan for ecotourism development in Bulgaria, 2009. State Agency for Tourism, Sofia, 8 pp. (in Bulgarian)

National programme and action plan for ecotourism development in Bulgaria, 2009. State Agency for Tourism. (in Bulgarian)

Rakadziyska Sv. I997. Alternative tourism. Sustainable tourism. Concepts and development conditions. At Publication of University of Economics, Varna, 3, 5-II. (In Bulgarian)

Rakadziyska Sv. 2007. Concepts fro development of sustainable and alternative tourism. At Introduction to Tourism, Publisher Science and economics, University of Economics Varna, Varna, I28-I32. (in Bulgarian) 